DOI: $10.1515 /$ hssr -2017-0027

HSS VI.3 (2017)

\title{
Investigating the Relationship Between Big Five Personality Traits and Cultural Intelligence on Football Coaches
}

\author{
Hassan Fahim Devin * \\ Islamic Azad University, Mashhad, Iran
}

\begin{abstract}
In this descriptive - correlative study we examined the relationship between big five personality traits with cultural intelligence in 113 active soccer coaches in the city of Mashhad in north-eastern of Iran. Anget. al (2004) cultural intelligence (CI) and Costa \& McCrae (1992) Revised NEO Personality Inventory (NEO-PI-R) and NEO Five-Factor Inventory (NEO-FFI questionnaires were used to obtain coaches' rate of cultural intelligence and personality traits. The results of the study revealed a significant positive relationship between personality traits (except for neuroticism) with Cultural intelligence. A significant reverse relationship was observed between neuroticism and Cultural intelligence. A significant difference was observed between coaches with $\mathrm{A}$ and $\mathrm{B}$ coaching degree, in comparison with $\mathrm{C}$ and $\mathrm{D}$ coaching degree in terms of cultural intelligence. No significant difference was observed between these two groups regarding personality traits. Our results show that some of the personality characteristics are crucial and related to a capability to function effectively in diverse settings.
\end{abstract}

Key words

cultural intelligence, personality traits, football coaches.

\section{Introduction}

As business, nowadays sport also operates in a multicultural world A British soccer team is owned by a Russian businessman, a Cameroonian

\footnotetext{
Department of Physical Education and Sport Science, Islamic Azad University, Mashhad Branch, Mashhad, Iran.; email: h.fahimdevin@gmail.com
} 
soccer player playing soccer in Germany, an American baseball coach on a mission to expand the game of baseball in China, coaches in China, a soccer player from Iran goes abroad to peruse his sport carrier, an Italian fencing expert from fencing federation on a mission to develop the sport in a different country takes up a new assignment. Even within a country itself a sport coach faces players with different backgrounds regarding their beliefs, values, attitudes, and so on.

We are all involved in a global world. Globalization means that countries, economies, industries and organizations can no longer rely on traditional boundaries. Globalization is the world's reality (Thomas and Inkson, 2004).

The day-to-day activities of global business involve interactions and relationships with people who are culturally diverse. Today in sport, as mentioned above, a coach might travel overseas to coach in different cultures and communicate with players and authorities from other cultures by phone or by email. Our Coaches in coaching business must acquire the ability to feel comfortable when dealing with people from other cultures, to know what to say, and to know how to behave.

A more compelling approach is to become culturally intelligent. Cultural intelligence is defined by theorists in many ways. Earley and Ang defined Cultural intelligence as the "capability of an individual to function effectively in situations characterized by cultural diversity" (Ang and Van Dyne, 2008).

\subsection{Cultural Intelligence}

Cultural intelligence is the ability to communicate with a new culture that is often unfamiliar with one's own culture (Early and Ang, 2003).Alon and Higgins (2005) began a study of global leadership success through emotional intelligence and cultural intelligence. The results showed that for foreign leaders' successful response to different environmental conditions and interpersonal relationships it is necessary to have high emotional and cultural intelligence.

There is a wide range of emotions in different cultures and even subcultures within a national culture, so that the difference in language, ethnicity, policies and many other properties can emerge as a potential conflict, and in case of lack of proper understanding, makes it difficult to 
develop good working relationships. Therefore, the effects of cultural differences and managing this kind of diversity represent a complex issue.

Ang and Van Dyne (2008) and Livermore (2009)describe four CQ capabilities: motivation (CQ Drive), cognition (CQ Knowledge), metacognition (CQ Strategy) and behavior (CQ Action). CQ Assessments report scores on all four capabilities as well as several sub-dimensions for each capability. The four capabilities stem from the intelligence-based approach to intercultural adjustment and performance.

CQ-Drive is a person's interest and confidence in functioning effectively in culturally diverse settings. It includes: Intrinsic Interest - deriving enjoyment from culturally diverse experiences Extrinsic Interest - gaining benefits from culturally diverse experiences Self-efficacy - having the confidence to be effective in culturally diverse situations

CQ-Knowledge is a person's knowledge about how cultures are similar and how cultures are different. It includes: Business - knowledge about economic and legal systems; Interpersonal - knowledge about values, social interaction norms, and religious beliefs; Socio-linguistics - knowledge about rules of languages and rules for expressing non-verbal behaviors.

CQ-Strategy is how a person makes sense of culturally diverse experiences. It occurs when people make judgments about their own thought processes and those of others. It includes: Awareness - knowing about one's existing cultural knowledge; Planning - strategizing before a culturally diverse encounter; Checking - checking assumptions and adjusting mental maps when actual experiences differ from expectations.

CQ-Action is a person's capability to adapt verbal and nonverbal behavior to make it appropriate to diverse cultures. It involves having a flexible repertoire of behavioral responses that suit a variety of situations. It includes: Non-Verbal - modifying non-verbal behaviors (e.g., gestures, facial expressions); Verbal - modifying verbal behaviors (e.g., accent, tone).

\subsection{Personality Traits}

Personality is defined as set of a stable tendencies and qualities which determine the behavioral-psychological similarities and differences (Thoughts - emotions -actions) of people, and may not be easily understood as the cognitive and social pressures of the time.

- Five Factor Model - classifies the personality of individuals 
according to five dimensions of extroversion, openness to new experiences, neuroticism, agreeableness, conscientiousness.

- EXTROVERSION - the tendency to be outgoing, energetic and sociable

- OPENNESS - the tendency to enjoy variety, novelty, challenge and intellectual stimulation

- NEUROTICISM - the tendency to experience unpleasant emotions

- AGREEABLENESS - the tendency to be friendly, compassionate and cooperative

- CONSCIENTIOUSNESS - the tendency to show self-discipline and self-control

Each of the individuals in terms of their personality, according to this model, can have a particular interest and attitude to the goals and tasks of the organization. However, to identify the factors affecting the working behavior, we should note other human variables, i.e. adaptability, occupational activities and the environment. If a person is eligible for verbal abilities, and motor skills, but his/her personality does not let $\mathrm{him} /$ her to adapt to the type of occupation, colleagues, clients, and other factors related to the working environment, again, he/she will not be able to do the task properly (McCrea and Tetracyano, 2005).

People are not the same in understanding foreign cultures and acting accordingly. Some people when going beyond their national and local culture, experience discomfort, uncertainty and inconsistency. In contrast, others will behave as if they have been used to foreign culture for many years. Galigiuri (2000) suggests that certain cultural properties should fit and match with certain cultural factors. During the research and development of his evolutionary theories, he proved the relationship between personality characteristics and cultural influences on the success of work.

A significant body of literature has examined the relationship between personality traits and Cultural intelligence. Studies by Peltokorpi (2008) found that personality traits impact cross - cultural adjustment dimensions. Research has found that personality and Cultural quotient are distinct although related constructs, each associated with its own unique set of individual differences. 


\subsection{Personality traits and Cultural intelligence}

Reviews of the personality literature have concluded that these personality dimensions are systematically linked to a variety of job performance criteria (Goldberg, 1993). The Big Five have been replicated in a variety of different languages and cultures, such as China (Trull\& Geary, 1997). The Big Five structure has also been tested across several cultures using an international English language scale (Thompson, 2008).

Researchers generally agree that the Big Five taxonomy of personality is important because of its ability to classify personality traits (Ang, Van Dyne \&Koh, 2006). The correlation of these personality factors with components of cultural intelligence provides valuable information as to the relationship between personality and cultural intelligence.

Ang et al (2006) in a study entitled "Personality correlates of the four factor model of Cultural Intelligence "examined relationship between Personality traits and four - factor model of Cultural Intelligence (meta cognitive CQ, motivational CQ, cognitive CQ and behavioral CQ)". Conscientiousness - one of the personality traits - was correlated with meta-cognitive CQ, agreeableness, and emotional Stability with behavioral CQ, extraversion with cognitive, behavioral and motivational CQ. The intriguing finding of this study was that Openness - one of the personality traits was significantly correlated with all four aspects of CQ.

Verghese and D" Netto (2011) in their research work "Cultural Intelligence and Openness: Essential Elements of Effective Global Leadership" found that the Big Five personal dimension called openness is essential for effective global leadership. They believe that global leaders who have a high level of cultural intelligence and openness will be extremely effective in this new global environment.

The results of a study by Huff et al. (2014) entitled "Cultural intelligence, personality, and cross - cultural adjustment: study of expatriates in Japan" indicate that motivational CQ can explain variance in expatriates' general interaction, and work adjustment over and above the five factor model of personality.

A study conducted by Harrison (2011) " Investigating the impact of personality and early life experiences on intercultural interaction in internationalized universities "revealed that both ethnocentrism and cultural intelligence were predicted by agreeableness and openness, as well 
as a multicultural upbringing, foreign language ability and an international orientation. Gender was also a predictor for ethnocentrism.

\section{Purpose of the study}

Based on research done in various contexts, the present study tries to investigate the relationship between big five personality traits and cultural intelligence on football coaches, and also compare these variables in coaches, coaching in late childhood and adolescence with youth and adulthood level and coaches with coaching degree of $A \& B$ with $C$ and D. The unique quality of this study lies in the fact that no such study has been done before in Iran. It is expected to serve as starting point for further study. Darwin from literature and based on the purposes of the study, the following hypotheses are proposed:

Hypothesis 1: there is a correlation between subscales of personality traits and cultural intelligence.

Hypothesis 2: there are differences in the rate of mean score of personality traits and cultural intelligence in coaches coaching in late childhood and adolescence with youth and adulthood level

Hypothesis 3: there are differences in the rate of mean score of personality traits and cultural intelligence in coaches with coaching degree of $\mathrm{A} \& \mathrm{~B}$ with $\mathrm{C}$ and $\mathrm{D}$.

\section{Methods}

\section{Sample}

Participants were 113 soccer coaches in different coaching levels who were selected out of 250 active coaches based on the Cochran sampling method.

\section{Measures}

Cultural Intelligence (CI)

Ang et al (2004) cultural intelligence (CI) questionnaire was used to obtain coaches' rate of cultural intelligence.

Personality Traits

Costa and McCrae (1992). Revised NEO Personality Inventory (NEOPI-R) and NEO Five-Factor Inventory (NEO-FFI) questionnaire was used to obtain data on coaches'dominant personality Traits type. 


\section{Findings}

\section{Descriptive statistics results}

The first statistical analysis to be performed was coefficient alpha to measure the reliability of the instruments. Although the instruments were proven to be reliable and have been used since the mid-twentieth century, reliability tests were needed for this study since the instruments were translated into Farsi, and were used in a different culture at a different span of time.

An internal consistency estimate was computed for two instruments and the alpha value for cultural Intelligence and personality traits were respectively 0.89 and 0.80 . All of these values were above the cut off value of 0.70 suggested by Nunnaly (1987).

Participants in this study were 113 coaches coaching in different sports, with different coaching degree and coaching in different age group. Mean of age was 36.9 with minimum age of 24 and maximum age of 55. Mean of coaches' cultural intelligence was 54.50 of max possible 100 , means of neuroticism was 41.29 , extraversion 36.20 , openness, 38.25 , agreeableness 37.35 and conscientiousness 35.73 of max possible 60 (Table 1).

Table 1: Descriptive statistics of Cultural intelligence and its subscales in active coaches

\begin{tabular}{|c|c|c|c|c|}
\hline Variable & M & SD & Minimum & Maximum \\
\hline $\begin{array}{c}\text { Cultural } \\
\text { intelligence }\end{array}$ & 54.50 & 20.36 & 20 & 100 \\
\hline Neuroticism & 41.29 & 8.60 & 12 & 60 \\
\hline Extraversion & 36.20 & 9.67 & 12 & 60 \\
\hline Agreeableness & 37.35 & 7.59 & 12 & 60 \\
\hline $\begin{array}{c}\text { Conscientious } \\
\text { ness }\end{array}$ & 35.73 & 8.57 & 12 & 60 \\
\hline
\end{tabular}

\section{Correlation results}

According to the correlation results in Table 2 no significant relationship was observed between neuroticism and cultural intelligence $(\mathrm{r}=-0.262, \mathrm{p}$-value $=0.60)$, but there was significant relationship between 
extraversion, agreeableness, conscientiousness and openness with cultural intelligence $(\mathrm{r}=0.576, \mathrm{p}$-value $=0.001, \mathrm{r}=0.556, \mathrm{p}$-value $=0.001, \mathrm{r}=0.565$, $\mathrm{p}$-value $=0.001, \mathrm{r}=0.514, \mathrm{p}$-value $=0.001)$.

Table 2. Correlations between personality traits and Cultural intelligence

\begin{tabular}{|c|c|c|c|}
\hline Variables & $\mathbf{N}$ & Correlation (r) & $\begin{array}{c}\text { p-value } \\
\text { (sig) }\end{array}$ \\
\hline $\begin{array}{c}\text { Neuroticism and Cultural } \\
\text { intelligence }\end{array}$ & 113 & -0.262 & 0.60 \\
\hline $\begin{array}{c}\text { Extraversion and Cultural } \\
\text { intelligence }\end{array}$ & 113 & 0.576 & 0.001 \\
\hline Openness and Cultural intelligence & 113 & 0.514 & 0.001 \\
\hline $\begin{array}{c}\text { Agreeableness and Cultural } \\
\text { intelligence }\end{array}$ & 113 & 0.556 & 0.001 \\
\hline $\begin{array}{c}\text { Conscientious and Cultural } \\
\text { intelligence }\end{array}$ & 113 & 0.565 & 0.001 \\
\hline
\end{tabular}

\section{Independent " $t$ " test results}

Table 3 displays significant differences at the level of $\alpha=0.05$ in the mean score of Cultural intelligence in coaches coaching in late childhood and adolescence, but no significant differences were found in these two groups regarding the personality traits.

Table 3. Comparison of variables in coaches coaching in late childhood and adolescence with youth and adulthood level

\begin{tabular}{|c|c|c|c|c|c|c|}
\hline Variables & Group & $\mathbf{N}$ & Mean & SD & $\begin{array}{l}\text { " } \mathrm{t} " \\
\text { value }\end{array}$ & $\begin{array}{c}\mathrm{p}- \\
\text { value }\end{array}$ \\
\hline \multirow{2}{*}{$\begin{array}{c}\text { Cultural } \\
\text { intelligence }\end{array}$} & $\begin{array}{l}\text { Coaching in late } \\
\text { childhood and } \\
\text { adolescence }\end{array}$ & 23 & 48.869 & 23.743 & \multirow[t]{2}{*}{0.321} & \multirow[t]{2}{*}{0.001} \\
\hline & $\begin{array}{l}\text { Coaching youth and } \\
\text { adulthood level }\end{array}$ & 81 & 54.308 & 19.630 & & \\
\hline \multirow{2}{*}{ Neuroticism } & $\begin{array}{l}\text { Coaching in late } \\
\text { childhood and } \\
\text { adolescence }\end{array}$ & 23 & 42.739 & 6.282 & \multirow{2}{*}{0.942} & \multirow{2}{*}{0.357} \\
\hline & $\begin{array}{c}\text { Coaching in youth } \\
\text { and adulthood } \\
\text { level }\end{array}$ & 84 & 40.964 & 8.588 & & \\
\hline
\end{tabular}


Hassan Fahim Devin, Investigating the Relationship between Big Five ...

HSS, vol. VI, no. 2 (2017): 116-131

\begin{tabular}{|c|c|c|c|c|c|c|}
\hline \multirow{2}{*}{ Extraversion } & $\begin{array}{l}\text { Coaching in late } \\
\text { childhood and } \\
\text { adolescence }\end{array}$ & 23 & 36.782 & 8.387 & \multirow{2}{*}{0.407} & \multirow{2}{*}{0.685} \\
\hline & $\begin{array}{l}\text { Coaching in youth } \\
\text { and adulthood } \\
\text { level }\end{array}$ & 84 & 35.892 & 9.507 & & \\
\hline \multirow{2}{*}{$\begin{array}{l}\text { Openness } \\
\text { to } \\
\text { experience }\end{array}$} & $\begin{array}{l}\text { Coaching in late } \\
\text { childhood and } \\
\text { adolescence }\end{array}$ & 23 & 37.913 & 7.076 & \multirow{2}{*}{0.274} & \multirow{2}{*}{0.784} \\
\hline & $\begin{array}{l}\text { Coaching in youth } \\
\text { and adulthood level }\end{array}$ & 84 & 38.381 & 7.289 & & \\
\hline \multirow{2}{*}{$\begin{array}{l}\text { Agreeablene } \\
\text { ss }\end{array}$} & $\begin{array}{l}\text { Coaching in late } \\
\text { childhood and } \\
\text { adolescence }\end{array}$ & 23 & 37.521 & 7.409 & \multirow{2}{*}{0.097} & \multirow{2}{*}{0.923} \\
\hline & $\begin{array}{l}\text { Coaching in youth } \\
\text { and adulthood }\end{array}$ & 84 & 37.357 & 7.118 & & \\
\hline \multirow{2}{*}{$\begin{array}{l}\text { Conscientio } \\
\text { usness }\end{array}$} & $\begin{array}{l}\text { Coaching in late } \\
\text { childhood and } \\
\text { adolescence }\end{array}$ & 23 & 35.956 & 0.183 & \multirow[t]{2}{*}{36.297} & \multirow[t]{2}{*}{8.376} \\
\hline & $\begin{array}{l}\text { Coaching in youth } \\
\text { and adulthood }\end{array}$ & 84 & 5.764 & 0.855 & & \\
\hline
\end{tabular}

Table 4 displays significant differences at the level of $\alpha=0.05$ in the mean score of Cultural intelligence in coaches with coaching degree of $\mathrm{A} \& \mathrm{~B}$ with $\mathrm{C}$ and $\mathrm{D}$, but no significant differences were found in these two groups regarding the personality traits.

Table 4. Comparison of variables in coaches with coaching degree of $A \& B$ with $C$ and $D$

\begin{tabular}{|c|c|c|c|c|c|c|}
\hline Variables & Group & $\mathbf{N}$ & Mean & SD & $\begin{array}{l}\text { " } t " \\
\text { value }\end{array}$ & p-value \\
\hline \multirow{2}{*}{$\begin{array}{l}\text { Cultural } \\
\text { intelligence }\end{array}$} & $\begin{array}{l}\text { Coaching degree of } \mathrm{A} \\
\text { and } \mathrm{B}\end{array}$ & 43 & 53.511 & 21.130 & \multirow{2}{*}{0.152} & \multirow{2}{*}{0.004} \\
\hline & $\begin{array}{l}\text { Coaching degree of } \mathrm{C} \\
\text { and } \mathrm{D}\end{array}$ & 61 & 47.131 & 20.059 & & \\
\hline \multirow{2}{*}{ Neuroticism } & $\begin{array}{l}\text { Coaching degree of } \mathrm{A} \\
\text { and } \mathrm{B}\end{array}$ & 46 & 40.172 & 9.329 & \multirow{2}{*}{0.883} & \multirow{2}{*}{0.379} \\
\hline & $\begin{array}{l}\text { Coaching degree of } \mathrm{C} \\
\text { and } \mathrm{D}\end{array}$ & 62 & 41.661 & 8.123 & & \\
\hline $\begin{array}{c}\text { Extraversio } \\
\mathrm{n}\end{array}$ & $\begin{array}{l}\text { Coaching degree of } \mathrm{A} \\
\text { and } \mathrm{B}\end{array}$ & 46 & 35.391 & 10.575 & 0.539 & 0.591 \\
\hline
\end{tabular}


Hassan Fahim Devin, Investigating the Relationship between Big Five ...

HSS, vol. VI, no. 2 (2017): 116-131

\begin{tabular}{|c|c|c|c|c|c|c|}
\hline & $\begin{array}{l}\text { Coaching degree of } \mathrm{C} \\
\text { and } \mathrm{D}\end{array}$ & 62 & 36.402 & 8.891 & & \\
\hline \multirow{2}{*}{$\begin{array}{l}\text { Openness to } \\
\text { experience }\end{array}$} & $\begin{array}{c}\text { Coaching degree of } \mathrm{A} \\
\text { and } \mathrm{B}\end{array}$ & 46 & 38.130 & 8.825 & \multirow{2}{*}{0.44} & \multirow{2}{*}{0.965} \\
\hline & $\begin{array}{c}\text { Coaching degree of } \mathrm{C} \\
\text { and } \mathrm{D}\end{array}$ & 62 & 38.064 & 6.750 & & \\
\hline \multirow{2}{*}{$\begin{array}{l}\text { Agreeablene } \\
\text { ss }\end{array}$} & $\begin{array}{c}\text { Coaching degree of } \mathrm{A} \\
\text { and } \mathrm{B}\end{array}$ & 46 & 36.978 & 8.657 & \multirow{2}{*}{0.304} & \multirow{2}{*}{0.762} \\
\hline & $\begin{array}{l}\text { Coaching degree of } \mathrm{C} \\
\text { and } \mathrm{D}\end{array}$ & 62 & 37.435 & 6.972 & & \\
\hline \multirow{2}{*}{$\begin{array}{l}\text { Conscientio } \\
\text { usness }\end{array}$} & $\begin{array}{l}\text { Coaching degree of } \mathrm{A} \\
\text { and } \mathrm{B}\end{array}$ & 46 & 34.673 & 8.819 & \multirow{2}{*}{1.300} & \multirow{2}{*}{0.196} \\
\hline & $\begin{array}{l}\text { Coaching degree of } \mathrm{C} \\
\text { and } \mathrm{D}\end{array}$ & 62 & 36.709 & 7.424 & & \\
\hline
\end{tabular}

\section{Discussion}

The result of the study revealed a significant positive relationship between personality traits (except for neuroticism) and Cultural intelligence. A significant reverse relationship was observed between neuroticism and Cultural intelligence (Table 2). In this regard it can be said that:

- People with neuroticism trait have low emotional stability and they are nervous, frustrated and disappointed, and they also tend not to communicate and interact with people from different cultures. On the contrary in people with high cultural intelligence, there is an inner motivation to interact with people from other cultures. It expresses the longing willingness for multicultural interaction and confidence that allows the individual to act effectively in cultural situations.

- Extroverted People are generally sociable, assertive, active, bold, adventuresome and expressive (Barrick et al., 2002). They are selfconfident, talkative and spontaneous. These personality characteristics allow them to vary their behavior more effectively than those who are less extroverted. They are therefore more likely to deal with novel and unfamiliar intercultural interactions more effectively than introverts who are more limited, uncertain and inhibited (Hogan, 1986). Moreover, the adventurous disposition of the extroverts increases the tendency for curiosity about other cultures and exposure to new situations, and motivates them to try to participate in different cultural experiences. Extroverted people, in the process of interaction with others, may learn 
and gain more knowledge about other cultures. Perhaps the positive relationship between extraversion and cultural intelligence is due to being easy-going, giving people the perception to have more interaction with people from different cultures. Studies conducted by Ang et al. (2005) also found the same results which is consistent with our findings.

- Coaches who are more flexible have more adaptability in intercultural interactions and they can establish effective and productive relationships in multicultural environments. Studies conducted by Van Diane and Ang (2005) obtained the same results.

- A coach with openness to experience personality dimension is someone who is intellectually curious, creative, innovative, imaginative, reflective and untraditional and tends to seek new experiences and explore new ideas. Such coaches can operate effectively in different cultures. According to the findings of Ang et al. (2006), openness to experience is a crucial personality characteristic that is related to a person's capability to function effectively in diverse cultural settings.

- People with Conscientiousness trait of personality are highly conscientious, competent, disciplined, goal seeking, and reliable (consultant) individuals. Dutifulness, in many organizational situations, is considered useful and important and coaches who have this trait can create balance in cultural heterogeneous environments in order for their team to achieve success. In studies conducted by Van Dyne and Ang (2005), as well, the same results are obtained. The results of this study are consistent with theirs.

- Agreeableness is a personality characteristic which enables a person to be generally friendly good natured, cooperative and flexible (Barrick and Mount, 1991; Goldberg, 1992; Hogan, 1986).Agreeable coaches are warm, likable, emotionally supportive and nurturing. In work contexts, employees with this characteristic show higher levels of interpersonal competency (Witt et al., 2002).This personality trait enables an individual to interact better with others in different social and cultural situations (Earley and Ang, 2003).

There was a significant difference between coaches coaching in late childhood and adolescence level and those working with the youth and adulthood age group.

- Means of cultural intelligence in coaches coaching in youth and 
adulthood was higher.

The reason for this contrast, is taking advantage of positive means to communicate effectively with young people and adults in teams that are culturally heterogeneous. Because the behavior of people in adulthood and youth age period is more stable than in late childhood and adolescence, hence, coaching in this level demands more professional skills and applying management tools such as more cultural intelligence. Coaches who are faced with young and adult individuals need to use more specific psychological skills and techniques to communicate, especially if they are present in multi-cultural environments. A coach must have a high public relations skill. He must be able to motivate his players in the best way possible. Between coaches coaching in these two age groups no difference was observed in terms of personality traits (neuroticism, extraversion, flexibility, taking responsibility and conscientiousness).

- Personality traits are not changeable by coaching classes. For example, it cannot be stated that coaches who work with teenagers are in a better condition in terms of personality traits. The fact that the coach works with a certain age group would not affect the characteristics of coaches which are the main elements of their personality. Personality traits suddenly and through facing a specific age group at work will not change.

There was difference between coaches with $\mathrm{A}$ and $\mathrm{B}$ coaching degree, in comparison with $\mathrm{C}$ and $\mathrm{D}$ coaching degree in terms of cultural intelligence. Coaches with $\mathrm{A}$ and $\mathrm{B}$ coaching degree had higher cultural quotient.

- Soccer is the game of moments. It is the game of mistakes. Soccer is a game of beliefs in which those who are bestowed more of the art of management achieve more success. Coaches play a crucial role in this game. Many compare soccer to playing chess, and believe that coaches who can better take advantage of their chessmen or players will achieve success sooner. He must be able to motivate the behavior of their players in the best possible way. Coaches with $\mathrm{A}$ and $\mathrm{B}$ coaching degree gained the degree after various steps and achieving a lot of experience in the international fields. These coaches certainly have different experiences in dealing with people from different cultures.

No significant difference was observed between coaches with $A$ and $B$ coaching degree in comparison with $\mathrm{C}$ and $\mathrm{D}$ coaching degree in regard to personality traits (neuroticism, extraversion, flexibility, taking responsibility, 
and conscientiousness).

- Coaches' coaching degree level would not change the personality traits. Although coaching is a career with constant change, personality traits are original and inherent elements of an individual, and these changes will not include the personality traits of the coach.

\section{Conclusion}

Big Five personality traits show adaptive mechanisms, which allow people to confront and respond to the demands of the physical, social, and cultural environment. Therefore, the five main personality traits are considered as an adaptive mechanism which puts a person exposed to behaviors that helps him to complete his missions in different situations. Second, while all people have some degrees of the five main factors of the universal adaptive mechanism, necessary personality traits for success to achieve the objectives are different in different people. Thus, those who have key personality traits for the given role in the physical or social environment are effectively more adaptable than those who lack the appropriate characteristics for the same role (Ang et al., 2001). Consequently, it can be said that certain personality traits are associated with cultural intelligence. Moreover, the results generally support the hypotheses.

As expected, the current study provides an insight into the relationships between certain aspects of the personality traits and cultural intelligence. Those who are successful in the planning, discipline and dutifulness are those who are also compatible in the field of intercultural interactions. Thus, dutifulness is positively associated with cultural intelligence. Agreeableness - one of the big five personality traits is positively related to cultural intelligence. This is acceptable, since adaptable people are basically permissive in their social behaviors, and show more flexibility in dealing with foreign cultures and they do not confront it but welcome it. People who score high in neuroticism are very emotionally reactive. They will have an emotional response to events that would not affect most people. A high scorer in neuroticism on a personality test has a greater chance of feeling threatened or being in a bad mood in a normal situation. They may find it difficult to think clearly and cope with stress. These people do not tend to interact with strange behavior that they have not encountered yet. Feelings 
are the necessary part of the change. Those who are extremely extroverted are good at cultural intelligence. Those who have confidence are looking for opportunities to interact and socialize with people from different cultural backgrounds, they learn about other cultures in the process, and they are cautious in speaking in order to demonstrate a flexible behavior. Finally, the freedom of experience (which is specified with curiosity, intellectual breadth and imagination) is associated with cultural intelligence. Openness to experience was one of the five main factors which is more important and related to cultural intelligence, and due to the nature of the increasingly dynamic and diverse work environments, adaptive functioning has emerged as a new form of job performance. Consequently, the results of this study proved a positive relationship between personality traits (except for neuroticism) and cultural intelligence (the ability to deal effectively with situations characterized by cultural diversity).

\section{References}

Alon, J. and Higgins, M. (2005). Globalleadership success through emotional and cultural Intelligences. Business Horizons.Vol. 48.501-512.

Ang, S., Van Dyne, L., Koh, C., Ng, K. Y., Templer, K. J., Tay, C. and Cahdrasekar, N. A.

(2001). Cultural intelligence: Its measurement and effects on cultural judgment and decision making, cultural adaptation, and task performance, Management and Organization Review. 3(3).335-371.

Ang, S., Van Dyne, L., Koh, C. and Ng, K. Y. (2005). The measurement of cultural intelligence, Academy of Management Meetings Symposium on Cultural Intelligence in the 21-Century, New Orleans, LA.

Ang, S., Van Dyne,L. and Koh, C . (2006). "Personality Correlates of the FourFactor Model of Cultural Intelligence”. Group Organization Management. 2006. 31; 100 .

Ang, S. and Van Dyne, L. (2008). Handbook of Cultural Intelligence, 1st ed. M.E. Sharpe.

Ang S. and Van Dyne, L. (2008). Conceptualization of cultural intelligence. Ang and Van Dyne (Eds.), Handbook of Cultural Intelligence: Theory, Measurement, and Applications, London: M.E. Sharpe, 3-15.

Barrick, M. R.and Mount, M. K. (1991). "The big five personality dimensions and job Performance". Personnel Psychology. 41: 1-26.

Barrick, M. R., Mount, M. K. and Piotrowski,M. (2002). Personality \& job performance. Test of the mediating effects of motivation among sales 
representatives.

Caligiuri, P. M. (2000). "Thebig five personality characteristics as predictors of expatriate's desire to terminate the assignment and supervisorated performance". Journal Personnel psychology. 53/ 67-88.

Costa, P.T.,Jr. and McCrae, R.R. (1992). Revised NEO Personality Inventory (NEOPI-R) and NEO Five-Factor Inventory (NEO-FFI) manual. Odessa, FL: Psychological Assessment Resources.

Earley P. C. and Ang, S. (2003). Cultural Intelligence: individual interactions across cultures. Stanford, CA.: Stanford BusinessBooks. 139-146.

Garivani, F., Fahim Devin, H., Farbod, D. (2016). 'Investigating the Relationship Between Group Emotional Intelligence with Collective Self-Efficacy and Team Work Effectiveness". Human and Social Studies. De Gruyter.5(2).133-144.

Fahim Devin, H., Farbod, D., Ghasabian, H., Bidel. T., Ghahremanlou, F. (2015). Comparative and Correlative Study of Psychological Hardiness and Competitiveness among Female Student Athletes in Individual and Team Sports". Sport Science Review. De Gruyter. 24(3-4), 201-213.

Gellatly, I. R. (1996). "Conscientiousness and task performance: Test of a cognitive process model". Journal of Applied Psychology. 37. 153-158.

Goldberg, L. R. (1992). "The development of markers of the Big-Five factor structure". Psychological Assessment. 4. 26-42.

Harrison, N. (2011). "Investigating the impact of personality and early life experiences on intercultural interaction in internationalized universities" (University of the West of England,Bristol, UK).

Hogan, R.(1986). Hogan Personality Inventory Manual. Minneapolis, MN: National Computer System.

Huff, K., Song,P. and Gresch, E.(2014). Cultural intelligence, Personality, Cross-cultural adjustment: A study of expatriates in Japan. Elsevier.Vol. 38.151-157.

Livermore, D. A., (2009), "Leading with Cultural Intelligence". New York: AMACOM.

McCrae, R. and Terracciano, A. (2005). "Universal Features of Personality Traits From the Observer's Perspective: Data From 50 Cultures", Journal of Personality and Social Psychology, 2005, Vol. 88, No. 3, 547-561.

Peltokorpi, V. (2008). "Cross-cultural adjustment of expatriates in Japan". The International Journal of Human Resource Management.19 (9).1588-1606.

Thomas, D. and Inkson, K. (2004). Cultural Intelligence. San Francisco: BerrettKoehler Publishers.

Trull T. J.and Geary D. C. (1997). "Comparison of the big-five factor structure across samples of Chinese and American adults". Journal of Personality Assessment.(2):324-41. 
Van Dyne, L. and Ang, S. (2005). Cultural Intelligence: An Essential Capability for Individuals in Contemporary Organizations. Global Edge.Msu.Edu.

Verghese, T. and D"Netto, B.(2011). "Cultural Intelligence and Openness: Essential Elements of Effective Global Leadership". International Review of Business, 7(1).191-200.

Ward, C. and Fischer, R. (2008). "Personality, cultural intelligence and crosscultural adaption". In Ang and Van Dyne (Eds.). Handbook of Cultural Intelligence: Theory, Measurement, and Applications, London: M.E. Sharpe, 159-173.

Witt, L. A., Burke, L. Barrik, M.R., and Mount, M. K. (2002). "The interactive effective of Conscientiousness and Agreeableness". Journal of Applied Psychology, 87,164-1699.

\section{Biographical note}

Hassan Fahim Devin, PhD, is currently an Assistant Professor of sport management at the Islamic Azad University - Mashhad Branch, Mashhad, Iran. He earned his Ph.D. in Sport Management at the Islamic Azad University Science and Research Branch, Tehran, Iran. His current research areas include Organizational Behavior. 